\title{
Studies of Electron Energy Distribution Function (EEDF) in Lithium Vapor Excitation at 2S $\rightarrow$ 3D Two-Photon Resonance
}

\author{
Mohamed A. Mahmoud1', Kholoud A. Hamam² \\ ${ }^{1}$ Physics Department, Faculty of Science, Sohag University, Sohag, Egypt \\ ${ }^{2}$ Physics Department, Sciences Faculty for Girls, King AbdUlaziz University, Jeddah, KSA \\ Email: hameideg@yahoo.com
}

Received 29 May 2014; revised 27 June 2014; accepted 23 July 2014

Copyright (C) 2014 by authors and Scientific Research Publishing Inc.

This work is licensed under the Creative Commons Attribution International License (CC BY). http://creativecommons.org/licenses/by/4.0/

(c) (i) Open Access

\begin{abstract}
We have developed a computational model which quantitatively studies the Electron Energy Distribution Function (EEDF) in laser excited lithium vapor at $2 \mathrm{~s} \rightarrow 3 \mathrm{~d}$ two-photon resonance. A kinetic model has been constructed which includes essentially all the important collisional ionization, photoionization, electron collisions and radiative interactions that come into play when lithium vapor (density range $10^{13}-10^{14} \mathrm{~cm}^{-3}$ ) is subject to a sudden pulse of intense laser radiation (power range $10^{5}-10^{6} \mathrm{~W} \cdot \mathrm{cm}^{-2}$ ) at wavelength $639.1 \mathrm{~nm}$ and pulse duration $20 \mathrm{~ns}$. The applied computer simulation model is based on the numerical solution of the time-dependent Boltzman equation and a set of rate equations that describe the rate of change of the formed excited states populations. Using the measured values for the cross-sections and rate coefficients of each physical process considered in the model available in literature, relations are obtained as a function of the electron energy and included in the computational model. We have also studied the time evolution and the laser power dependences of the ion population (atomic and molecular ions) as well as the electron density which are produced during the interaction. The energy spectra of the electrons emerging from the interaction contains a number of peaks corresponding to the low-energy electrons produced by photoionization and collisional ionization such as assosicative and Penning ionization processes. The non-equilibrium shape of these electrons occurs due to relaxation of fast electrons produced by super-elastic collisions with residual excited lithium atoms. Moreover, a reasonable agreement between McGeoch results and our calculations for the temporal behaviour of the electron density is obtained.
\end{abstract}

\section{Keywords}

Two-Photon Resonance Excitation, Laser, Lithium, Collisional Ionization, Energy Pooling Photoionization, Electron Energy Distribution Function 


\section{Introduction}

Generation of plasma in gases by intense laser pulses is a well-known optical phenomenon. The efficiency of this process can be increased by many orders of magnitude when the laser wavelength corresponds to an absorption line of ionized medium [1]. Laser-produced plasma sources are currently being developed to generate photons at a $13.5 \mathrm{~nm}$ wavelength to continue the development of faster computer chips. Utilizing the smallest wavelength for extreme ultraviolet lithography projection is the path to future progress in semiconductor technology [2].

On one hand, the electron energy distribution function is a topic of continuing interest to the plasma physics, fusion, and astrophysical communities because they can play an important role in the formation, evolution, and radiative properties of a wide variety of plasma sources. Non-Maxwellian electron energy distributions have been predicted or detected in diverse laboratory sources including tokomaks [3] [4], laser plasmas [5]-[7] and pulsed-power plasmas [8]-[10] as well as in astrophysical sources such as solar flares [11] [12] and active galactic nuclei [13], where they are generated by strong electric fields or resonant laser-plasma interactions. On the other hand, measurements of the EEDF are important for many applications, such as studies of absolute negative conductivity in photo plasma. This effect was predicted in the medium of a $\mathrm{Li}+\mathrm{Ar}+\mathrm{N}_{2}$ mixture under optical resonant excitation of the $2 s \rightarrow 2 p$ transition in lithium [14] [15]. The additional interest in the EEDF for the photo plasma is related to the light-to-electric signal conversion [16] [17].

Two-photon excitation of $\mathrm{Li}(3 \mathrm{~d})$ state is a starting point for a variety of processes in lithium vapor. Under conditions of high atom densities $\left(10^{15} \mathrm{~cm}^{-3}\right)$ and laser powers $\left(10^{6} \mathrm{~W} \cdot \mathrm{cm}^{-2}\right)$, this excitation plays an important role in laser plasma production [18]-[20]. Recently, Labazan and Milosevic [21] studied the processes which occurred in lithium vapor under two-photon excitation of the $\mathrm{Li}(3 \mathrm{~d})$ state at $639.1 \mathrm{~nm}$. In their experiment they used a pulsed dye laser pumped with excimer laser to excite the $\mathrm{Li}(3 \mathrm{~d})$ level by two-photon absorption at 639.1 $\mathrm{nm}$. Density of lithium vapor was in the range $\left(10^{13}-10^{14} \mathrm{~cm}^{-3}\right)$ and laser powers $\left(10^{5}-10^{6} \mathrm{~W} \cdot \mathrm{cm}^{-2}\right)$. The laser pulse duration was about $20 \mathrm{~ns}$ (FWHM), laser repetition rate was usually $5 \mathrm{~Hz}$ and the pulse energy was measured in the range $1-4 \mathrm{~mJ}$ at $639.1 \mathrm{~nm}$. They had measured the radiation rates from lithium atomic states populated by two-photon excitation.

Theoretical modeling of alkali metal vapor ionization under resonant optical excitation was carried out in [22]-[25]. It was shown that there existed a competition of several ionization reactions: two-photon ionization of resonant states, associative resonant states, direct ionization by electron impact of the ground state, the resonant-state stepwise ionization by electron impact and photionization from high-lying excited states by resonance radiation.

More recently, Mahmoud et al. [26] presented a computational model to study the collisional ionization processes which occurred under $2 s \rightarrow 2 p$ excitation of lithium vapor excited with a nanosecond pulsed laser. Our interest in this work is primary to investigate the Electron Energy Distribution Function (EEDF) in lithium vapour excitation at $2 \mathrm{~s} \rightarrow 3 \mathrm{~d}$ two-photon resonance to determine conditions (namely lithium atom densities, laser energy, etc.) for the excitation processes because of its eventual importance in understanding ionization-guiding discharge experiments. This work studies two main subjects:

1) The influence of the ionization processes on the EEDF shape and the electron density in laser excited lithium by two-photon.

2) The dependence of EEDF and the ion density on the laser power and the lithium vapor density. In addition, we compare our results with that calculated by McGeoch [24]. The article is organized in the following way. In Section 2, we present theoretical model which includes the physical processes and the rate equations and the mathematical formula of the rate coefficients used to describe expected processes. In Section 3, we show our calculation results along with a discussion of various processes involved. Finally our conclusions are presented in Section 4.

\section{The Theoretical Model of Laser Excited Lithium Vapour 2S $\rightarrow$ 3D Transition}

The energy level structure of lithium atom is well known [26]. Its low ionization potential provides little obstacles for multiphoton excitation and ionization. In the study of Labazan and Milosevic [21] Xe-Cl excimer laser pumped dye laser is used for the ionization of lithium vapor. Two photons at $639.1 \mathrm{~nm}$ will excite the lithium atom from the ground state $2 \mathrm{~S}$ to the excited state 3D. Another $639.1 \mathrm{~nm}$ photon will ionize the lithium atom. The two-photon excitation rate $W^{(2)}$ in $\left(\mathrm{s}^{-1}\right)$ can be written as: 


$$
W^{(2)}=\sigma_{(2)} F^{2}
$$

where $\sigma_{(2)}$ and $F$ represent the two-photon excitation cross section and the photon flux density respectively. The photon flux is given by,

$$
F\left[\frac{\text { photon }}{\mathrm{cm}^{2} \cdot \mathrm{sec}}\right]=\frac{I}{h v}=3.3 \times 10^{18} \cdot I\left[\mathrm{~W} \cdot \mathrm{cm}^{-2}\right]
$$

In this section, we consider the processes which occur in lithium vapour under two-photon excitation of the $\mathrm{Li}(3 \mathrm{D})$ state at $639.1 \mathrm{~nm}$. The molecular channel does not contribute to ionization processes according to the experimental conditions [20] [21].

\subsection{Process Considered}

1) The absorption of resonant photon.

$$
\mathrm{Li}(2 \mathrm{~s})+2 \mathrm{~h} v_{639.1} \rightarrow \operatorname{Li}(3 \mathrm{~d})
$$

2) Photon ionization of the $\mathrm{nl}$ level.

$$
\mathrm{Li}(\mathrm{nl})+\mathrm{h} v_{639.1} \rightarrow \mathrm{Li}^{+}+\mathrm{e}
$$

3) Associative ionization of 3d-3d collision.

$$
\mathrm{Li}(3 \mathrm{~d})+\mathrm{Li}(3 \mathrm{~d}) \rightarrow \mathrm{Li}_{2}^{+}+\mathrm{e}
$$

4) Collisional ionization (Penning ionization).

$$
\mathrm{Li}(3 \mathrm{~d})+\mathrm{Li}(3 \mathrm{~d}) \rightarrow \mathrm{Li}^{+}+\mathrm{Li}(2 \mathrm{~s})+\mathrm{e}
$$

5) Reverse Energy pooling collisions.

$$
\operatorname{Li}(3 d)+\operatorname{Li}(2 s) \rightarrow \operatorname{Li}(2 p)+\operatorname{Li}(2 p)
$$

6) Radiative decay of Li(3d).

$$
\mathrm{Li}(3 \mathrm{~d}) \rightarrow \mathrm{Li}(2 \mathrm{p})+\mathrm{h} v_{610.4 \mathrm{~nm}}
$$

7) Energy pooling collisions.

$$
\operatorname{Li}(2 p)+\operatorname{Li}(2 p) \rightarrow \operatorname{Li}(3 d, 3 p)+\operatorname{Li}(2 s)
$$

8) Super elastic collision (SEC):

The super elastic collision is described by the collision of a low energy electron with an excited atom. This process can be written as:

$$
\mathrm{Li}(\mathrm{nl})+\mathrm{e}\left(\varepsilon_{\mathrm{o}}\right) \rightarrow \mathrm{Li}(2 \mathrm{~s})+\mathrm{e}(\varepsilon) \text { where } \varepsilon>\varepsilon_{0} .
$$

9) Electron impact excitation:

This process is the inverse of superelastic collision process,

$$
\mathrm{Li}(\mathrm{nl})+\mathrm{e}(\varepsilon) \rightarrow \operatorname{Li}\left(\mathrm{n}^{\prime} \mathrm{l}^{\prime}\right)+\mathrm{e}\left(\varepsilon_{\mathrm{o}}\right) \text { where } \varepsilon>\varepsilon_{0} .
$$

10) Electron impact ionization.

When an electron gains enough energy (through super-elastic collisions), which is equal to the ionization potential of the neutral atom, It can undergo an ionizing collision by electron impact process, resulting in a low energy electron of $\left(\varepsilon=\varepsilon_{1}+\varepsilon_{2}+\mathrm{E}_{\text {ion }}\right)$ and atomic ion.

$$
\mathrm{Li}(\mathrm{nl})+\mathrm{e}(\varepsilon) \rightarrow \mathrm{Li}^{+}+\mathrm{e}\left(\varepsilon_{1}\right)+\mathrm{e}\left(\varepsilon_{2}\right)
$$

where $\varepsilon=\varepsilon_{1}+\varepsilon_{2}+\mathrm{E}_{\text {ion }}$ and $\mathrm{E}_{\text {ion }}$ is the ionization energy.

11) Radiative recombination.

$$
\mathrm{Li}^{+}+\mathrm{e}(\varepsilon) \rightarrow \mathrm{Li}(\mathrm{nl})+\mathrm{h} v
$$


12) Three-body recombination.

$$
\mathrm{Li}^{+}+\mathrm{e}\left(\varepsilon_{1}\right)+\mathrm{e}\left(\varepsilon_{2}\right) \rightarrow \mathrm{Li}(\mathrm{nl})+\mathrm{e}(\varepsilon)
$$

where $3 \mathrm{~s} \leq n \mathrm{l} \leq 7 \mathrm{~d}$.

For simplicity we have assumed that $\varepsilon_{1}=\varepsilon_{2}$ in the electron impact ionization and its inverse three-body recombination processes. There are several assumptions which we use for mathematical description of excitation and ionization processes.

\subsection{Rate Equations}

The rate of change of population density of state $2 \mathrm{~s}, 2 \mathrm{p}, 3 \mathrm{~d}$ and the highly excited states $\mathrm{nl}$ is given by,

$$
\begin{gathered}
\frac{\mathrm{d} N(2 s)}{\mathrm{d} t}=N(3 d)\left(W_{51}+A_{51}\right)-N(2 s) W_{15}+N(3 p) A_{41}+N(2 p) A_{21} \\
-N(2 s) n_{e}(\varepsilon) k_{15}(\varepsilon)+N(3 d) n_{e}(\varepsilon) k_{51}(\varepsilon)+\frac{1}{2} N^{2}(3 d) k_{P I} \\
+\frac{1}{2} N^{2}(2 p) k_{E P}-N(2 s) N(3 d) k_{R E P}-N(2 s) n_{e}(\varepsilon) k_{1 c}(\varepsilon) \\
\frac{\mathrm{d} N(2 p)}{\mathrm{d} t}= \\
+\frac{1}{2} N^{2}(3 d) A_{52}-N(2 p) n_{e}(\varepsilon) k_{21}(\varepsilon)+N(2 s) n_{e}(\varepsilon) k_{12}(\varepsilon) \\
-N(2 p) \sigma_{2 c}^{(1)} F-N(2 s) n_{e}(\varepsilon) k_{2 c}(\varepsilon) \\
\frac{\mathrm{d} N(3 d)}{\mathrm{d} t}=N(2 s) W_{15}-N(3 d)\left(W_{51}+A_{51}\right)-N(3 d) A_{52}+N(2 s) n_{e}(\varepsilon) k_{15}(\varepsilon) \\
-N(3 d) n_{e}(\varepsilon) k_{51}(\varepsilon)-\frac{1}{2} N(3 d)^{2} k_{A I}-\frac{1}{2} N(3 d)^{2} k_{P I}-N(3 d) \sigma_{5 c}^{(1)} F \\
-\frac{1}{2} N^{2}(2 p) k_{E P}-N(2 s) N(3 d) k_{R E P}-N(3 d) n_{e}(\varepsilon) k_{5 c}(\varepsilon) \\
\frac{\mathrm{d} N(n)}{\mathrm{d} t}=\sum_{n>m} N(n) n_{e}(\varepsilon) k_{n m}(\varepsilon)-\sum_{m>n} N(m) n_{e}(\varepsilon) k_{m n}(\varepsilon)-\sum_{n>m} A_{n m} N(n)-\sum_{n} N(n) n_{e}(\varepsilon) k_{n c}(\varepsilon) \\
-\sum_{n>2} N(n) \sigma_{n c}^{(1) 1 c p} F+N_{\mathrm{Li}}{ }^{+} n_{e}(\varepsilon) \sum_{n}\left[n_{e}(\varepsilon) k_{c n}(\varepsilon)+k_{R D}(\varepsilon)\right]
\end{gathered}
$$

The rate of growth of the molecular ion and the atomic ion is given by,

$$
\begin{gathered}
\frac{\mathrm{d} N\left(\mathrm{Li}_{2}^{+}\right)}{\mathrm{d} t}=\frac{1}{2}(N(3 d))^{2} k_{A I} \\
\frac{\mathrm{d} N\left(\mathrm{Li}^{+}\right)}{\mathrm{d} t}=\frac{1}{2} N^{2}(3 d) k_{P I}+\sum_{n>2} N(n) \sigma_{n c}^{(1)} F+\sum_{n} N(n) n_{e}(\varepsilon) k_{n c}(\varepsilon)
\end{gathered}
$$

where,

$\mathrm{N}(2 \mathrm{~s}), \mathrm{N}(2 \mathrm{p}), \mathrm{N}(3 \mathrm{~d})$ and $\mathrm{N}(\mathrm{n})$ are the population density of levels 2s, 2p, 3d and nl, respectively.

$\mathrm{n}_{\mathrm{e}}(\varepsilon)$ represents the electron density as a function of electron energy $(\varepsilon)$.

$\mathrm{W}_{15}$ is the stimulated absorption rate coefficient from $2 \mathrm{~s}$ to $3 \mathrm{~d}$ level $\left(\mathrm{sec}^{-1}\right)$.

$\mathrm{W}_{51}$ is the stimulated emission rate coefficient from $3 \mathrm{~d}$ to $2 \mathrm{~s}$ level $\left(\mathrm{sec}^{-1}\right)$.

$A_{21}$ Einstein coefficient for spontaneous emission for the transition $2 \mathrm{p}$ to $2 \mathrm{~s}\left(\mathrm{sec}^{-1}\right)$.

$A_{51}$ Einstein coefficient for spontaneous emission for the transition (3d to 2s) $\left(\mathrm{sec}^{-1}\right.$ ).

$\mathrm{A}_{41}$ Einstein coefficient for spontaneous emission for the transition 3p to $2 \mathrm{~s}\left(\mathrm{sec}^{-1}\right)$.

$\mathrm{A}_{52}$ Einstein coefficient for spontaneous emission for the transition $3 \mathrm{~d}$ to $2 \mathrm{p}\left(\mathrm{sec}^{-1}\right)$. 
$A_{n m}$ Einstein coefficient for spontaneous emission for the transition $n \rightarrow m\left(\sec ^{-1}\right)$.

$\mathrm{k}_{\mathrm{EP}}$ represents the energy pooling collisions rate coefficient $\left(\mathrm{cm}^{3} \cdot \mathrm{sec}^{-1}\right)$.

$\mathrm{k}_{\mathrm{REP}}$ represents the reverse energy pooling collisions rate coefficient $\left(\mathrm{cm}^{3} \cdot \mathrm{sec}^{-1}\right)$.

$\mathrm{k}_{\mathrm{AI}}$ represents the association ionization rate coefficient $\left(\mathrm{cm}^{3} \cdot \mathrm{sec}^{-1}\right)$.

$\mathrm{k}_{\mathrm{PI}}$ represents Penning ionization rate coefficient for level $\mathrm{n}\left(\mathrm{cm}^{3} \cdot \mathrm{sec}^{-1}\right)$.

$k_{51}$ represents the electron collision rate coefficient for transition from $(3 d \rightarrow 2 s)$ as a function of electron energy $(\varepsilon)\left(\mathrm{cm}^{3} \cdot \mathrm{sec}^{-1}\right)$.

$\mathrm{k}_{15}$ represents the electron collision rate coefficient for transition from $(2 \mathrm{~s} \rightarrow 3 \mathrm{~d})$ as a function of electron energy $(\varepsilon)\left(\mathrm{cm}^{3} \cdot \mathrm{sec}^{-1}\right)$.

$\mathrm{k}_{5 c}$ represents electron collision ionization rate coefficient for level $3 \mathrm{~d}\left(\mathrm{~cm}^{3} \cdot \mathrm{sec}^{-1}\right)$.

$\mathrm{k}_{1 \mathrm{c}}$ represents electron collision ionization rate coefficient for level $2 \mathrm{~s}\left(\mathrm{~cm}^{3} \cdot \mathrm{sec}^{-1}\right)$.

$\mathrm{k}_{\mathrm{nc}}(\varepsilon)$ represents electron collision ionization rate coefficient for level $\mathrm{n}\left(\mathrm{cm}^{3} \cdot \mathrm{sec}^{-1}\right)$.

$\mathrm{k}_{\mathrm{nm}}$ represents the electron collision rate coefficient for transition from $(\mathrm{n} \rightarrow \mathrm{m})$ as a function of electron energy $(\varepsilon)\left(\mathrm{cm}^{3} \cdot \sec ^{-1}\right)$.

$\mathrm{k}_{\mathrm{mn}}(\varepsilon)$ represents the electron collision rate coefficient for transition from $(\mathrm{m} \rightarrow \mathrm{n})$ as a function of electron energy $(\varepsilon)\left(\mathrm{cm}^{3} \cdot \sec ^{-1}\right)$.

$\sigma_{\mathrm{nc}}^{(1)}$ represents the photon ionization cross-section for level $\mathrm{n}\left(\mathrm{cm}^{2}\right)$.

$\sigma_{2 c}^{(1)}$ represents the single photon ionization cross-section for level $2 \mathrm{p}\left(\mathrm{cm}^{2}\right)$.

$\mathrm{k}_{\mathrm{cn}}$ represents the three body recombination rate coefficient for level $\mathrm{n}\left(\mathrm{cm}^{6} \cdot \mathrm{sec}^{-1}\right)$.

$\mathrm{k}_{\mathrm{RD}}$ represents the radiative recombination rate coefficient $\left(\mathrm{cm}^{3} \cdot \mathrm{sec}^{-1}\right)$.

$\mathrm{N}_{\mathrm{Li}^{+}}$represents the density of atomic ions.

$\mathrm{N}_{\mathrm{Li}_{2}^{+}}$represents the density of molecular ions.

$\mathrm{F}$ is the photon flux (photon/( $\left.\mathrm{cm}^{2} \cdot \mathrm{sec}\right)$ ).

The electron energy distribution function equation (EEDF) is given by:

$$
\begin{aligned}
\frac{\mathrm{d} n_{e}(\varepsilon)}{\mathrm{d} t}= & \sum_{m>n} N(m) n_{e}(\varepsilon) k_{n m}(\varepsilon)-\sum_{m<n} N(n) n_{e}(\varepsilon) k_{m n}(\varepsilon) \\
& +\sum_{n} N(n) n_{e}(\varepsilon) k_{n c}(\varepsilon)+\frac{1}{2} N^{2}(3 d) k_{P I}+\frac{1}{2} N^{2}(3 d) k_{A I} \\
& +\sum_{n>2} N(n) \sigma_{n c}^{(1)} F-N_{\mathrm{Li}^{+}} n_{e}(\varepsilon) \sum_{n}\left[n_{e}(\varepsilon) k_{c n}(\varepsilon)+k_{R D}(\varepsilon)\right]
\end{aligned}
$$

The normalization conditions are given by:

$$
\begin{gathered}
N_{0}=\sum_{n} N(n)+N\left(\mathrm{Li}^{+}\right) \\
\int_{0}^{\infty} n_{e}(\varepsilon) \varepsilon^{1 / 2} \mathrm{~d} \varepsilon=1
\end{gathered}
$$

where $N_{0}$ is the density of $\mathrm{Li}$ atomic vapour. Note that the factor $1 / 2$ with $k_{E P}$ and $k_{A I}$ corrects for possible double counting of each colliding pair of identical particles [27].

\subsection{Effects of EEDF on Collisional Rates}

To calculate the electron energy distribution function, numerous data have to be compiled from the literature to be fed into the Boltzmann equation computational code [28]. By the use of suitable approximations for the energy dependence of the cross sections, the rate coefficients can be expressed by simple analytical formula. The rates of collisional process in plasma are given by the product of the plasma electron density $n_{e}$ and the rate coefficient $\langle v \sigma\rangle$ of the particular process. The rate coefficient is determined by integrating an energy-dependent collision cross section $\sigma(\varepsilon)$ over the electron energy distribution function [29].

$$
\langle v \sigma\rangle=\int_{\Delta E}^{\infty} v \sigma(\varepsilon) f(\varepsilon) \mathrm{d} \varepsilon\left[\mathrm{cm}^{3} \cdot \mathrm{s}^{-1}\right]
$$

where $v$ and $\varepsilon$ are the velocity and energy, of the incident electron respectively. The lower limit of the integration is the threshold energy of the process for collisional excitation and ionization. 
For single-temperature plasmas with Maxwellian electron energy distributions, de-excitation and recombination rates can be obtained directly from collisional excitation and ionization rate coefficients through detailed balance. For plasmas that have electrons in non-Maxwellian distributions, the cross sections of these reverse rates must be integrated over the entire electron energy distribution. By the use of suitable approximation for the energy dependence of the cross sections, the corresponding rate coefficients can be expressed by simple analytical formula.

The cross sections for excitation by electron impact $\sigma_{\mathrm{nm}}^{\mathrm{ex}}$ are linearly approximated in the energy range of interest [29]:

$$
\sigma_{\mathrm{nm}}^{\mathrm{ex}}(\varepsilon)=\mathrm{C}_{\mathrm{nm}}\left(\varepsilon-\varepsilon_{\mathrm{s}}\right) \quad \varepsilon>\varepsilon_{\mathrm{s}}=E_{n}-E_{m}
$$

Here, $\mathrm{C}_{\mathrm{nm}}$ is the excitation cross section constant and $\varepsilon_{\mathrm{s}}$ the energy threshold. The excitation rate coefficient is obtained by integration with respect to Maxwellian energy distribution:

$$
k_{n m}=4\left(\frac{k_{B} T_{e}}{2 \pi m_{e}}\right)^{1 / 2} C_{n m}\left(\varepsilon_{s}+2 k_{B} T_{e}\right) \exp \left[-\varepsilon_{s} / k_{B} T_{e}\right]
$$

The rate coefficient $k_{m n}$ for the reverse reaction, superelastic collisions is obtained by the principle of detailed balance as follows:

$$
k_{n m}=k_{m n} \frac{g_{m}}{g_{n}} \exp \left[\left(E_{n}-E_{m}\right) / k_{B} T\right]
$$

where $g_{n}$ and $g_{m}$ are the statistical weights of the upper and lower levels, respectively.

For the ionization of excited states by electron impact we use the empirical formula given by Vriens and Smeets [30] for the cross section and rate coefficients:

$$
\sigma_{n c}=\frac{6.5 \times 10^{-14}}{\varepsilon+3.25 E_{i}}\left(\frac{5}{E_{i}}-\frac{1}{\varepsilon}-\frac{2 E_{i}}{3 \varepsilon^{2}}\right)
$$

where $E_{i}=5.18-E_{n} \varepsilon \geq E_{i}$.

The reverse reaction, recombination by a three-particle collision, is obtained by the detailed balancing of ionization:

$$
\frac{k_{\mathrm{nc}}}{k_{\mathrm{cn}}}=\left(\frac{2 \pi m_{e}}{h^{2}}\right)^{3 / 2} \frac{2 g_{+}}{g_{n}} \exp \left[\frac{-E_{+n}}{k_{\mathrm{B}} T_{e}}\right]
$$

where $g_{n}$ and $g_{+}$are the statistical weights of the neutral atomic and the atomic ion respectively.

For the radiative recombination rate coefficients we have used the empirical formula given by Drawin [31]:

$$
\begin{gathered}
k_{r d}=2.07 \times 10^{-11} Z^{2} T_{e}^{-\frac{1}{2}} \varphi\left(u_{x}\right) \\
\varphi\left(u_{x}\right)=-\sum_{n=1} \frac{u_{x}}{n^{3}} \mathrm{e}^{\left(\frac{u_{x}}{n^{2}}\right)} E_{n}\left(-\frac{u_{x}}{n^{2}}\right)
\end{gathered}
$$

and $u_{x}=1.58 \times 10^{5} \quad E_{i}^{H}=13.59 \mathrm{eV}, Z$ is the atomic number of the neutral atom and $T$ is the gas temperature in $\mathrm{K}^{\circ}$.

On the other hand the values of the rate coefficients of collisional ionization, energy pooling collisions and processes in our model are indicated in Table 1.

\section{Results and Discussion}

The set of equations which was mentioned previously is solved numerically under the experimental conditions of Labazan and Milosevic [21]. In this instance the initial lithium vapor density was assumed to be $3 \times 10^{13}-7 \times$ $10^{14} \mathrm{~cm}^{-3}$, the laser power changes from $1 \times 10^{5}$ to $1 \times 10^{6} \mathrm{~W} \cdot \mathrm{cm}^{-2}$, the temperature varied from $760 \mathrm{~K}^{\circ}-880 \mathrm{~K}^{\circ}$ and the energy of single pulse (E) varied from $1 \rightarrow 4 \mathrm{~m}$ Joule. The laser intensity (I) is given by $\mathrm{I}=\frac{E}{\tau \times \pi r^{2}}$, 
Table 1. Kinetic processes in lithium ionization model.

\begin{tabular}{|c|c|c|}
\hline Process & Cross Section & Reference \\
\hline Two photon absorption $\sigma_{(2)}: \operatorname{Li}(2 s)+2 h v \rightarrow \operatorname{Li}(3 d)$ & $6.25 \times 10^{-31} \mathrm{~cm}^{4} \cdot \mathrm{s}$ & {$[32]$} \\
\hline Spontaneous emission for the transition $2 \mathrm{p} \rightarrow 2 \mathrm{~s}: \mathrm{A}_{21}$ & $0.186 \times 10^{7} \mathrm{sec}^{-1}$ & [33] \\
\hline Spontaneous emission for the transition $3 \mathrm{~d} \rightarrow 2 \mathrm{p}: \mathrm{A}_{52}$ & $2.389 \times 10^{7} \mathrm{sec}^{-1}$ & [33] \\
\hline Spontaneous emission for the transition $3 \mathrm{p} \rightarrow 2 \mathrm{~s}: \mathrm{A}_{42}$ & $0.39 \times 10^{6} \mathrm{sec}^{-1}$ & [33] \\
\hline Spontaneous emission for the transition $3 \mathrm{~d} \rightarrow 2 \mathrm{~s}: \mathrm{A}_{51}$ & $2.53 \times 10^{2} \mathrm{sec}^{-1}$ & [34] \\
\hline Associative ionization $\mathrm{k}_{\mathrm{Al}}: \mathrm{Li}(3 \mathrm{~d})+\mathrm{Li}(3 \mathrm{~d}) \rightarrow \mathrm{Li}_{2}^{+}+\mathrm{e}^{-}$ & $7 \times 10^{-14} \mathrm{~cm}^{2}$ & [35] \\
\hline Penning ionization $\mathrm{k}_{\mathrm{pl}}: \mathrm{Li}(3 \mathrm{~d})+\mathrm{Li}(3 \mathrm{~d}) \rightarrow \mathrm{Li}^{+}+\mathrm{Li}(2 \mathrm{~s})+\mathrm{e}^{-}$ & $14 \times 10^{-14} \mathrm{~cm}^{2}$ & [35] \\
\hline Energy pooling $k_{\mathrm{EP}}: \mathrm{Li}(2 \mathrm{p})+\mathrm{Li}(2 \mathrm{p}) \rightarrow \mathrm{Li}(3 \mathrm{p}, 3 \mathrm{~d})+\mathrm{Li}(2 \mathrm{~s})$ & $7.8 \times 10^{-15} \mathrm{~cm}^{2}$ & [36] \\
\hline Reverse Energy pooling $K_{\text {REP }}: \operatorname{Li}(3 p, 3 d)+\operatorname{Li}(2 s) \rightarrow \operatorname{Li}(2 p)+\operatorname{Li}(2 p)$ & $6 \times 10^{-16} \mathrm{~cm}^{2}$ & [37] \\
\hline Single photon ionization 3s & $1.48 \times 10^{-18} \mathrm{~cm}^{2}$ & [38] \\
\hline Single photon ionization $4 \mathrm{~s}$ & $1.40 \times 10^{-18} \mathrm{~cm}^{2}$ & [38] \\
\hline Single photon ionization $5 \mathrm{~s}$ & $1.33 \times 10^{-18} \mathrm{~cm}^{2}$ & [38] \\
\hline Single photon ionization $2 p$ & $12.50 \times 10^{-18} \mathrm{~cm}^{2}$ & [38] \\
\hline Single photon ionization $3 p$ & $28.10 \times 10^{-18} \mathrm{~cm}^{2}$ & [38] \\
\hline Single photon ionization $4 p$ & $41.7 \times 10^{-18} \mathrm{~cm}^{2}$ & [38] \\
\hline Single photon ionization $5 p$ & $56.2 \times 10^{-18} \mathrm{~cm}^{2}$ & [38] \\
\hline Single photon ionization 3d & $18.2 \times 10^{-18} \mathrm{~cm}^{2}$ & [38] \\
\hline Single photon ionization $4 \mathrm{~d}$ & $36.2 \times 10^{-18} \mathrm{~cm}^{2}$ & [38] \\
\hline
\end{tabular}

where $\tau$ is the laser pulse duration and $r$ is the laser beam radius. Under these conditions, the laser light was tuned to the two-photon resonance $2 \mathrm{~s} \rightarrow 3 \mathrm{~d}$, at $\lambda=639.1 \mathrm{~nm}$. The rate equation for the electron energy distribution function (8) is divided into 54 equations, where the ionization energy of $\mathrm{Li}=5.39 \mathrm{eV}$ and the energy step equal $0.1 \mathrm{eV}$. We calculate 1 ) the electron energy distribution function and its dependence on the laser intensity and lithium vapor density., 2) the effect of laser power and the time on the atomic ion $\left(\mathrm{Li}^{+}\right)$and the molecular ion $\left(\mathrm{Li}_{2}^{+}\right), 3$ ) the effect of laser power and the lithium vapor density on the time evolution of the electron density which generated during the laser interaction with lithium vapor.

\subsection{The Dependence of the Electron Energy Distribution Function on the Lithium Atomic Vapor and Laser Power}

The electron energy distribution function as a function of lithium atomic vapor after 20 ns and laser power $1 \times$ $10^{5} \mathrm{~W} \cdot \mathrm{cm}^{-2}$ is plotted and shown in Figure 1. From this figure we note that the spectral structure is observed with certain peaks (A, B, C, D, and E) lying at energies $0.35,1.1,1.75,2.5$ and $3 \mathrm{eV}$ respectively. The energy distribution of the electrons produced in peak $\mathrm{A}$ is centering at a mean energy $\mathrm{E} \approx 0.35 \mathrm{eV}$ by photon ionization processes which is described by the following equation.

$$
\mathrm{Li}(3 \mathrm{~d}, 3 \mathrm{p}, 3 \mathrm{~s})+\mathrm{hv}_{639.1} \rightarrow \mathrm{Li}^{+}+\mathrm{e}
$$

Also the peak B corresponds to electrons produced by photon ionization processes of (5s, 4d, 4p, 4s).

$$
\mathrm{Li}(5 \mathrm{~s}, 4 \mathrm{~d},, 4 \mathrm{p}, 4 \mathrm{~s})+\mathrm{hv}_{639.1} \rightarrow \mathrm{Li}^{+}+\mathrm{e}
$$

While the peak C corresponds to single photon ionization. 


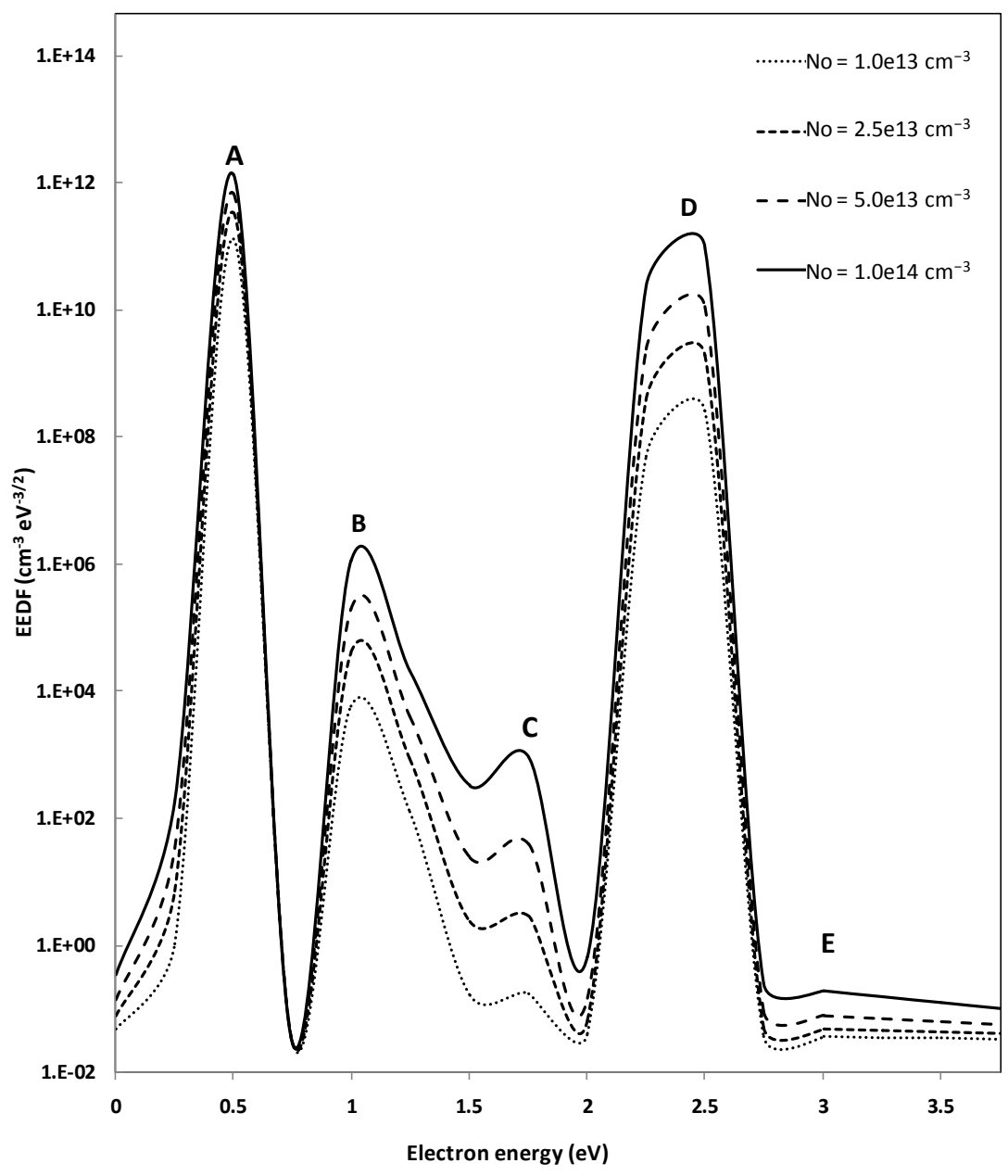

Figure 1. The dependence of the Electron Energy Distribution Function on the lithium vapor density after $20 \mathrm{n} \mathrm{sec}$ from the laser pulse and laser power $1 \times 10^{5} \mathrm{~W} \cdot \mathrm{cm}^{-2}$.

$$
\mathrm{Li}(5 \mathrm{p})+\mathrm{h} v_{639.1} \rightarrow \mathrm{Li}^{+}+\mathrm{e}
$$

The peak D corresponds to the electrons produced by Penning and associative ionization of Li(3d) which described by the following collision.

$$
\begin{gathered}
\mathrm{Li}(3 \mathrm{~d})+\mathrm{Li}(3 \mathrm{~d}) \rightarrow \mathrm{Li}^{+}+\mathrm{Li}(2 \mathrm{~s})+\mathrm{e} \\
\mathrm{Li}(3 \mathrm{~d})+\mathrm{Li}(3 \mathrm{~d}) \rightarrow \mathrm{Li}_{2}^{+}+\mathrm{e}
\end{gathered}
$$

While the peak $\mathrm{E}$ is attributed to the superelastic collisions.

$$
\mathrm{Li}(\mathrm{nl})+\mathrm{e}\left(\varepsilon_{\mathrm{o}}\right) \rightarrow \mathrm{Li}(2 \mathrm{~s})+\mathrm{e}(\varepsilon) \text { where } \varepsilon>\varepsilon_{0} .
$$

We assume that the interaction started with the absorption of laser photons by $\mathrm{Li}(2 \mathrm{~s})$ excited to $\mathrm{Li}(3 \mathrm{~d})$ through two-photon resonance process. We assume that the most important source of population of the $\mathrm{Li}(3 \mathrm{~d})$ state is the laser excitation, atoms can make many interactions like Penning, associative ionization, photoionization, decay to $\operatorname{Li}(2 \mathrm{p})$ (life time $\tau_{3 \mathrm{~d}-2 \mathrm{p}}=16.7 \mathrm{~ns}$ [20], may collide with $\mathrm{Li}(2 \mathrm{~s})$ in reverse energy pooling reaction to form $\mathrm{Li}(2 \mathrm{p}$ ) atoms which is the main source of highly excited atoms through energy pooling interactions, also $\mathrm{Li}(3 \mathrm{~d})$ atoms may collide with $\mathrm{Li}(2 \mathrm{~s})$ to create $\mathrm{Li}(3 \mathrm{p})$ through energy transfer collisions [21], finally super elastic collisions and photoionization processes of all excited states can take place during the interaction.

The dependence of the electron energy distribution function on the laser power after 20 ns and lithium vapor density $3 \times 10^{13} \mathrm{~cm}^{-3}$ is indicated in Figure 2. From this figure we show that, as the laser power increases, the 


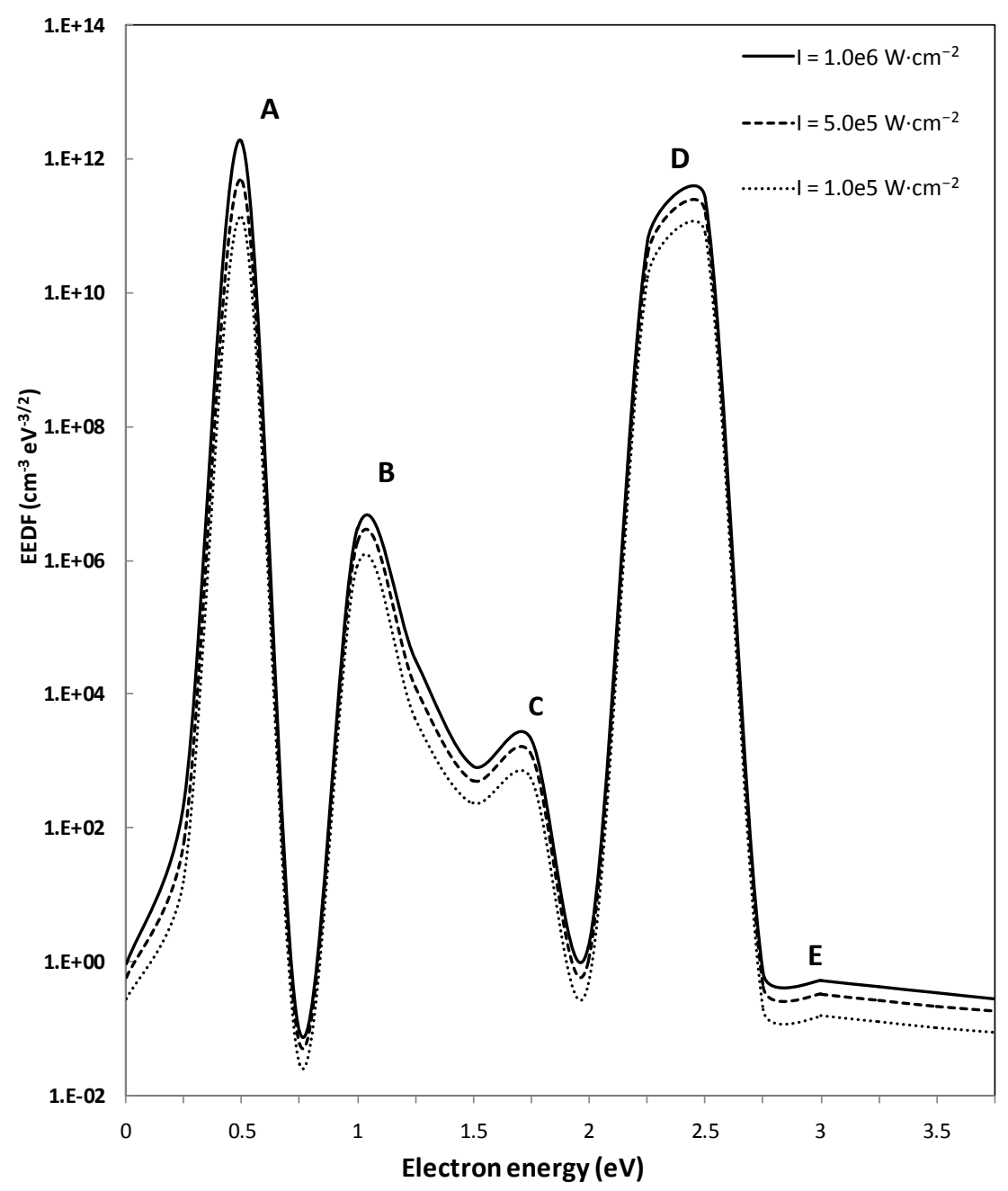

Figure 2. Electron Energy Distribution Function after $20 \mathrm{n}$ sec from the laser pulse at different values of laser power and lithium vapor density $3 \times 10^{13} \mathrm{~cm}^{-3}$.

value of the electron energy distribution increases at EEDF corresponding to peaks, B, C and E. This result indicates the dependence of the occurrence of some physical processes on the laser power which turn results in the appearance of such peaks in EEDF. These peaks are attributed to some physical processes which contribute to the population and depopulation of the various excited states considered in this analysis. The figures illustrates the role of the photoioniation process in EEDF formation in the case when $\mathrm{J}_{\mathrm{ph}}$ is for an order of magnitude greater than the ionization flux due to electron impact $\mathrm{J}_{\mathrm{ei}}=\mathrm{k}_{\mathrm{c}, 2 \mathrm{p}} \mathrm{N}(2 \mathrm{p}) \mathrm{n}_{\mathrm{e}}$. Photoionization from the Li (3P) and $\mathrm{Li}(3 \mathrm{~d})$ states produces electrons with energy $\sim 0.3 \mathrm{eV}$. As one can see, a peak is formed on EEDF around this energy. However the interesting point from our point of view is that, the photoionization and collisional ionization are the dominant processes during the plasma formation in laser excited lithium atoms [15] [16].

\subsection{The Dependence of the Atomic Ions $\left(\mathrm{Li}^{+}\right)$Density on the Atomic Lithium Vapor and Laser Power}

The growth rate of the atomic ions $\left(\mathrm{Li}^{+}\right)$density as a function of lithium vapor density is shown in Figure 3 for different values of irradiation time. From this figure it can be seen that the atomic ions $\left(\mathrm{Li}^{+}\right)$density show that as the lithium density increases the ion density $\mathrm{Li}^{+}$increases and the curves show almost the same behavior with descending values of lithium vapor density for different values of time. Also it is observed that the density of atomic ions $\left(\mathrm{Li}^{+}\right)$increases with the laser power as indicates in Figure 4 for different values of time. This behavior is due to the $\mathrm{Li}^{+}$mainly produced by the photoionization and laser induced Penning ionization processes 


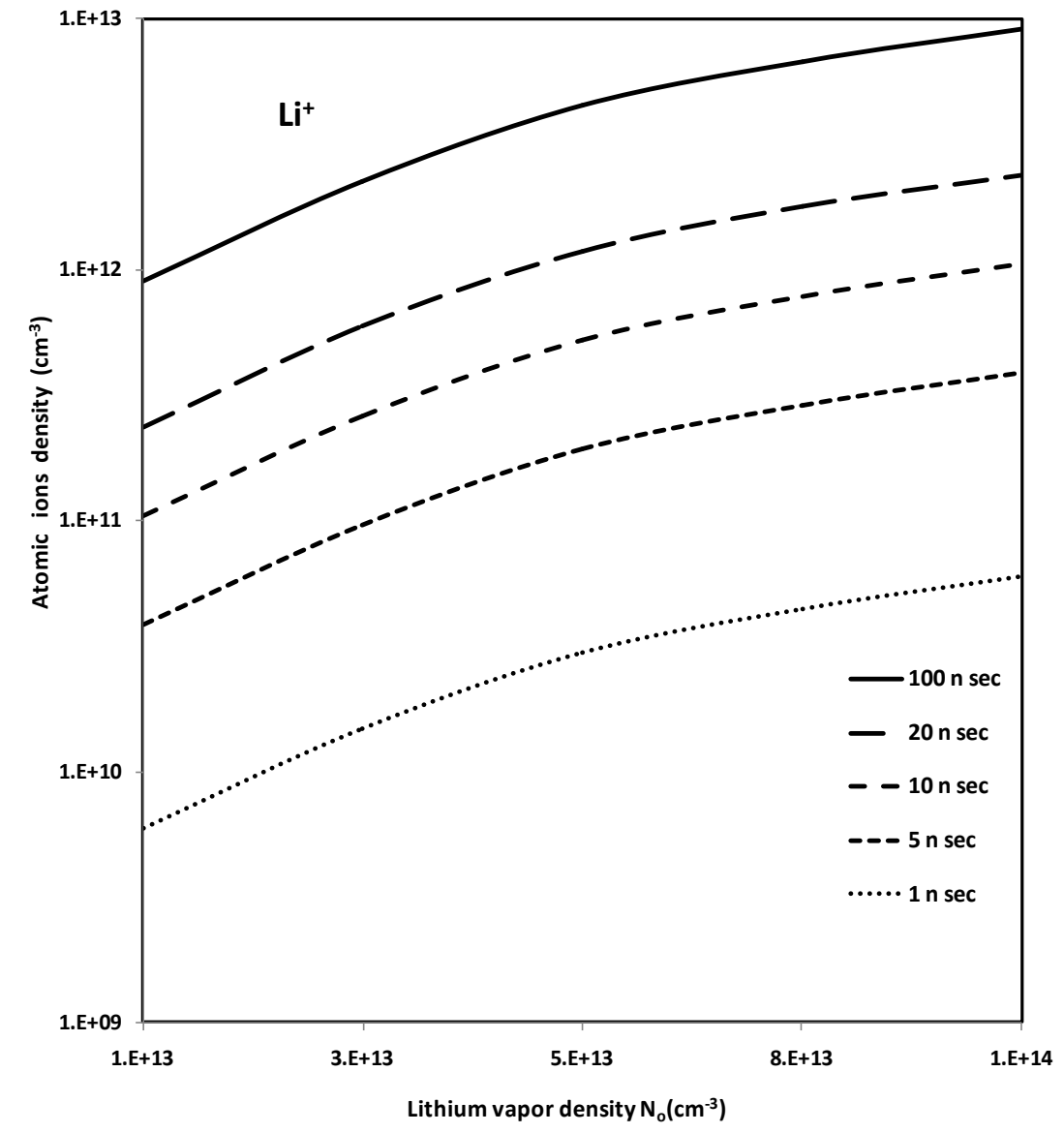

Figure 3. Variation of Atomic ions density $\mathrm{Li}^{+}$with Lithium vapor density $\mathrm{N}_{0}$ at different time intervals and laser power $1 \times 10^{5} \mathrm{~W} \cdot \mathrm{cm}^{-2}$.

[17]. Collisions of highly-excited atoms with resonantly excited ones may result in Penning ionization where nl states are populated in energy pooling collisions of two Li(2p) atoms [21].

\subsection{The Time Evolution of the Atomic Ion $\mathrm{Li}^{+}$}

The growth rate of the $\mathrm{Li}^{+}$as a function of time is indicated in Figure 5 for different values of laser power. From this figure it can be seen that the $\left(\mathrm{Li}^{+}\right)$shows a fast increase during the early stages of the interaction up to $5 \mathrm{~ns}$ followed by a linear increase up to $10 \mathrm{~ns}$. Immediately after this time the density of $\mathrm{Li}^{+}$density shows a slow increase during the late stage of the irradiation time. This behavior is due to the $\mathrm{Li}^{+}$mainly produced by the Penning ionization and photionization processes as follows:

$$
\begin{aligned}
\mathrm{Li}(3 \mathrm{~d})+\mathrm{Li}(3 \mathrm{~d}) & \rightarrow \mathrm{Li}^{+}+\mathrm{Li}(2 \mathrm{~s})+\mathrm{e} \\
\mathrm{Li}(\mathrm{nl})+\mathrm{h} v & \rightarrow \mathrm{Li}^{+}+\mathrm{e} \quad(\mathrm{PHO})
\end{aligned}
$$

where $\mathrm{nl}$ states are populated in energy pooling collisions of two $\mathrm{Li}(3 \mathrm{~d})$ atoms:

$$
\mathrm{Li}(2 \mathrm{p})+\mathrm{Li}(2 \mathrm{p}) \rightarrow \mathrm{Li}(\mathrm{nl})+\mathrm{Li}(2 \mathrm{~s})
$$

In general the figure shows the same behavior for almost values of the irradiation time.

\subsection{The Molecular ions $\left(\mathrm{Li}_{2}^{+}\right)$Density as a Function of Lithium Vapor Density}

Density of the molecular ions $\left(\mathrm{Li}_{2}^{+}\right)$variation with lithium vapor density is illustrated in Figure 6 at laser power $1 \times 10^{5} \mathrm{~W} \cdot \mathrm{cm}^{-2}$. From this figure we can see that the $\mathrm{Li}_{2}{ }^{+}$density increases rapidly with increasing of 


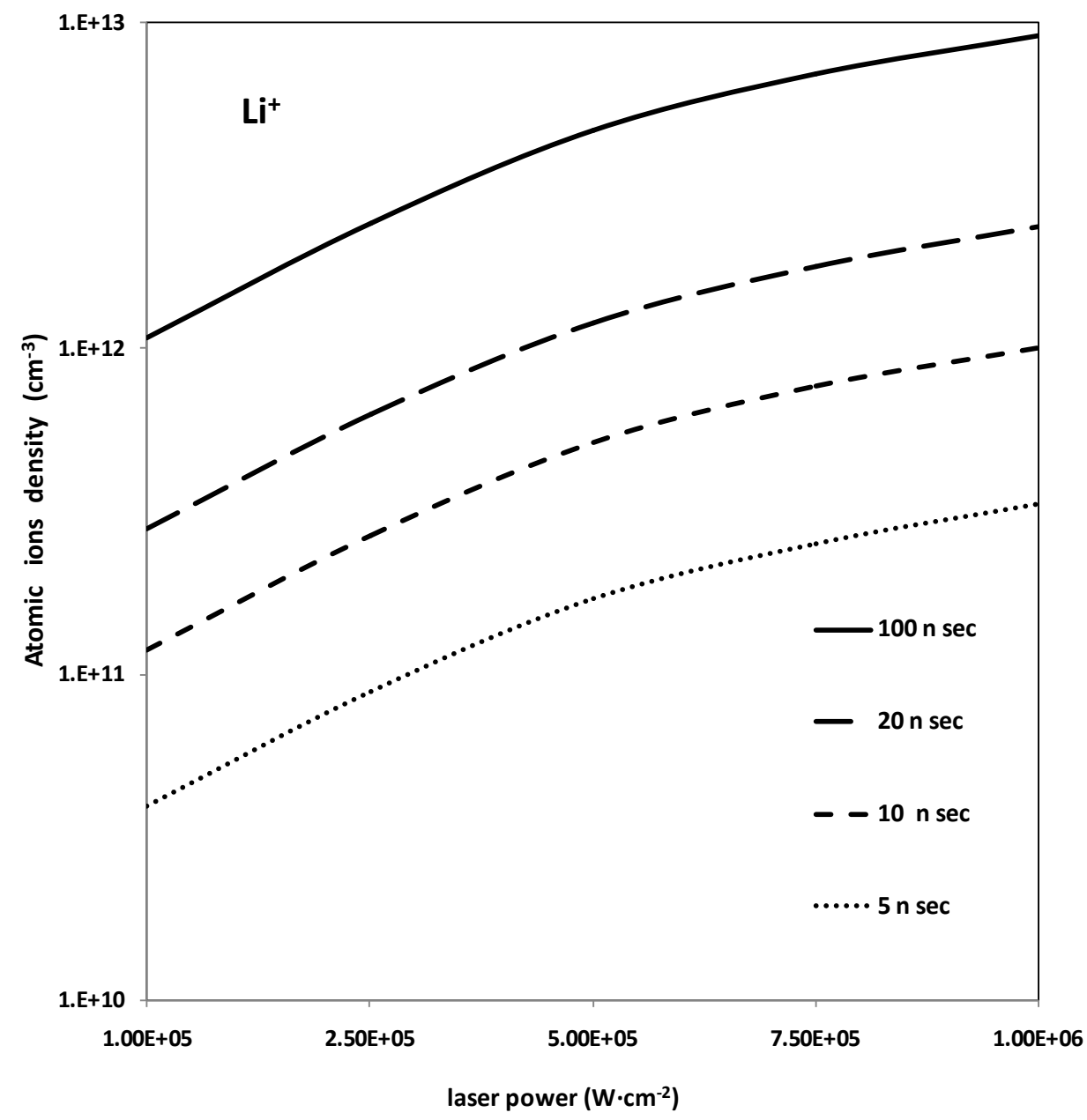

Figure 4. Variation of Atomic ions density $\mathrm{Li}^{+}$with laser power at different time intervals and lithium vapour density $7 \times 10^{14} \mathrm{~cm}^{-3}$.

lithium vapor density, while the density of molecular ions is approximately constant with the variation of laser power where the molecular ions are produced from associative ionization (AI). On the hand, in lithium unlike the rest of the alkali metals, the reaction of the association ionization of two resonant excited atoms is not important at $\mathrm{T}$ (gas temperature) $<0.1 \mathrm{eV}$, due to a considerable energy deficit $(\sim 0.7 \mathrm{eV})$ which diminishes its efficiency [16].

\subsection{The Time Evolution of the Molecular Ion $\mathrm{Li}_{2}^{+}$}

The growth rate of the molecular ion $\mathrm{Li}_{2}^{+}$as a function of time is illustrated in Figure 7 for different values of laser power. From this figure, we can see that the $\mathrm{Li}_{2}^{+}$density shows a fast increase during the period $0.1 \mathrm{~ns}$ up to $5 \mathrm{~ns}$ followed by a linear increase up to $20 \mathrm{~ns}$. Immediately after this time the $\mathrm{Li}^{+}{ }_{2}$ density shows a slow increase during the late stages of the irradiation time. An understanding of this behavior can be attained by considering that the main processes for producing these molecular ions are associative ionization (AI) process as follows:

$$
\mathrm{Li}(3 \mathrm{~d})+\mathrm{Li}(3 \mathrm{~d}) \rightarrow \mathrm{Li}_{2}^{+}+\mathrm{e}\left(\varepsilon_{\mathrm{v}}\right)(\mathrm{AI})
$$

where $\varepsilon_{\mathrm{V}}$ is the kinetic energy of the free electrons emitted when $\mathrm{Li}_{2}^{+}$ion formed in the mean relative kinetic energy of the colliding atoms in the beam. Generally, the linear shape of $\mathrm{Li}_{2}^{+}$and the linear and quadratic term exchange show that the only possible mechanism for producing the molecular ion is (AI) at a certain density of $\mathrm{Li}$ atomic vapor. 


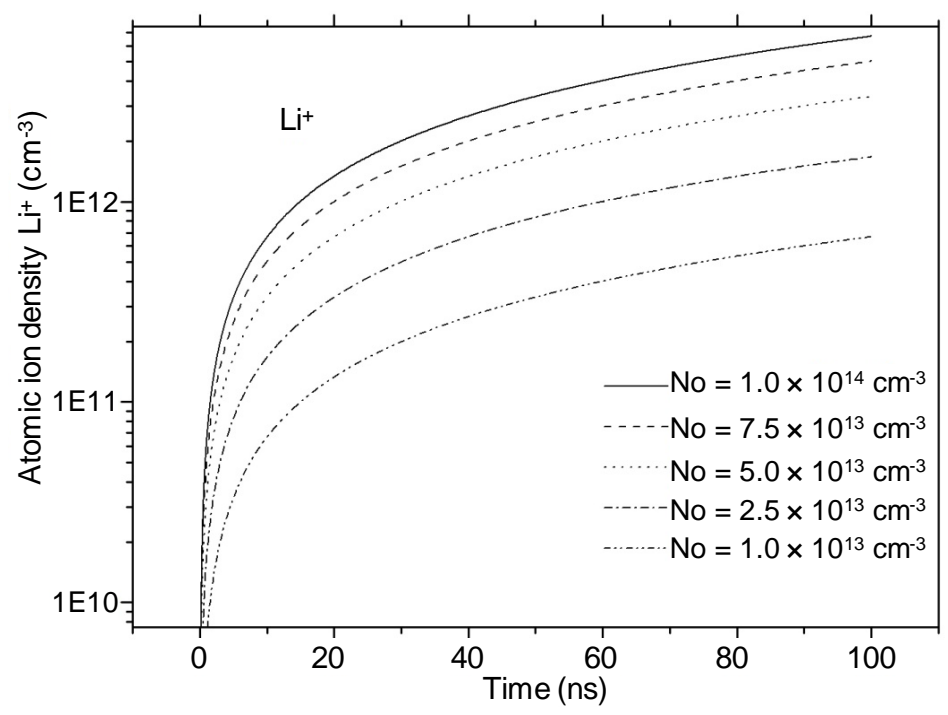

Figure 5. Time evolution of Atomic ion $\mathrm{Li}^{+}$at different lithium vapor densities and laser power $1 \times 10^{5} \mathrm{~W} \cdot \mathrm{cm}^{-2}$.

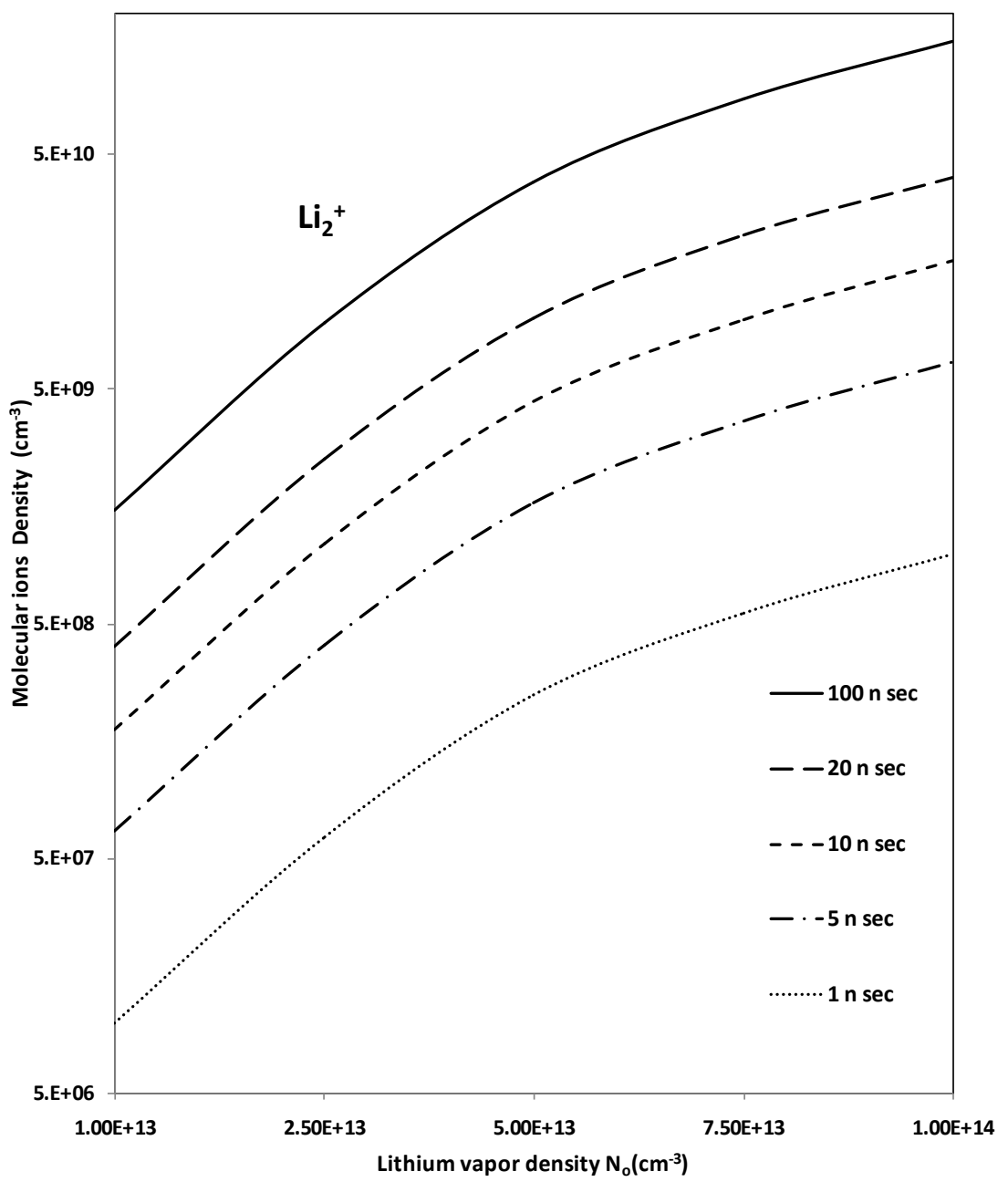

Figure 6. Variation of molecular ion density $\mathrm{Li}_{2}{ }^{+}$with Lithium vapor density $\mathrm{N}_{0}$ at different time intervals and laser power $1 \times 10^{5} \mathrm{~W} \cdot \mathrm{cm}^{-2}$. 


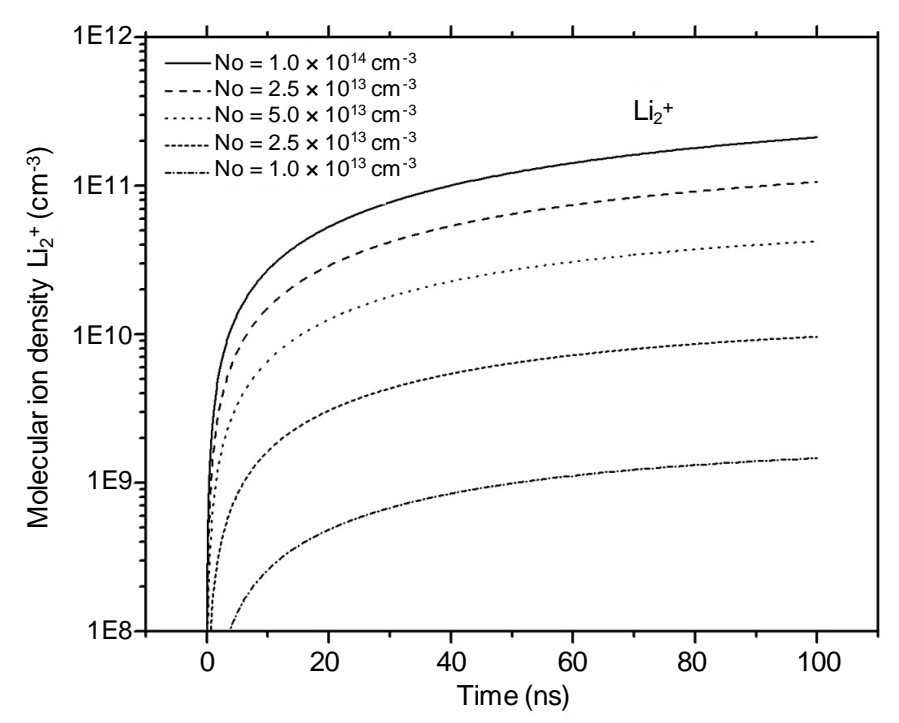

Figure 7. Time evolution of Molecular ion $\mathrm{Li}_{2}^{+}$at different lithium vapor densities and laser power $1 \times 10^{5} \mathrm{~W} \cdot \mathrm{cm}^{-2}$.

\subsection{The Dependence of the Electron Density $\left(\mathrm{N}_{\mathrm{e}}\right)$ on the Atomic Lithium Vapor and Laser Power}

Variation of electrons density with lithium vapor density is shown in Figure 8, the curves show that $\mathrm{N}_{\mathrm{e}}$ is directly proportional to the lithium vapor at laser power $1 \times 10^{5} \mathrm{~W} \cdot \mathrm{cm}^{-2}$. Also Figure 9 shows the dependence of the electron density of the laser power at constant lithium vapor density. From this figure, we note that as the laser increases the density of the electron $\mathrm{N}_{\mathrm{e}}$ increases and the curves show the same behavior with descending values of the laser power for the different periods of irradiation time. Moreover, at high laser power greater than $10^{5} \mathrm{~W} \cdot \mathrm{cm}^{-2}$ we note a very fast increase in the electron density. The explanation of this behavior is attributed to the main physical processes which produce the $\mathrm{N}_{\mathrm{e}}$ are the photoionization and collisional ionization processes. On the other hand under the resonant radiation the ionization goes from $\mathrm{Li}(3 \mathrm{p}), \mathrm{Li}(3 \mathrm{~d})$ and also from the higher lying states, the photoionization flux from the $\mathrm{k}_{\mathrm{th}}$ level $\Phi_{\mathrm{ph}}=\sigma_{\mathrm{ph}}^{\mathrm{k}} \mathrm{n}_{\mathrm{k}} \mathrm{F}$ is proportional to the ionization cross section $\sigma_{\mathrm{ph}}^{\mathrm{k}}$, to the level population $\mathrm{n}_{\mathrm{k}}$ and to the photon flux density $\mathrm{F}=\int \mathrm{I}(\mathrm{v}) \mathrm{dv} /(\mathrm{hv})$, where $\mathrm{I}\left(\mathrm{W} \cdot \mathrm{cm}^{-2}\right)$ is the incident radiation density. For the conditions under consideration one can expect the maximal population for the states situated near resonant excited $\mathrm{Li}(3 \mathrm{~d})$ level, which is why the total ionization rate is determined by the ionization from $\mathrm{Li}(3 \mathrm{p})$ and $\mathrm{Li}(3 \mathrm{~d})$ states. The energy gap between these two levels is $0.045 \mathrm{eV}$.

\subsection{The Time Evolution of the Electron Density $\mathrm{N}_{\mathrm{e}}$}

The growth rate of electrons $\mathrm{N}_{\mathrm{e}}$ as a function of time is indicted in Figure $\mathbf{1 0}$ for different values of lithium vapor density. From this figure, we can see that, the electron density increase up to $20 \mathrm{~ns}$. Immediately after this time the electron density shows a slow increase during the late stages of the interaction. The explanation of the linear growth can be described as follows, after the absorption of two-photon resonance,

$$
\mathrm{Li}(2 \mathrm{~s})+2 \mathrm{~h} v_{639.1 \mathrm{~nm}} \rightarrow \mathrm{Li}(3 \mathrm{~d})
$$

ions can be created by following paths.

The first is a photoionization of the $3 \mathrm{~d}$ level:

$$
\mathrm{Li}(3 \mathrm{~d})+\mathrm{h} v_{639.1 \mathrm{~mm}} \rightarrow \mathrm{Li}^{+}+\mathrm{e}
$$

The second path is reverse energy pooling or spontaneous decay of $\operatorname{Li}(3 \mathrm{~d})$ to form $\mathrm{Li}(2 \mathrm{p})$ followed by energy pooling of $\mathrm{Li}(2 \mathrm{p})$ atoms to form higher excited states like (3d, 3p, ...) level followed by photoionization:

$$
\mathrm{Li}(3 \mathrm{~d})+\mathrm{Li}(2 \mathrm{~s}) \rightarrow \mathrm{Li}(2 \mathrm{p})+\mathrm{Li}(2 \mathrm{p})
$$




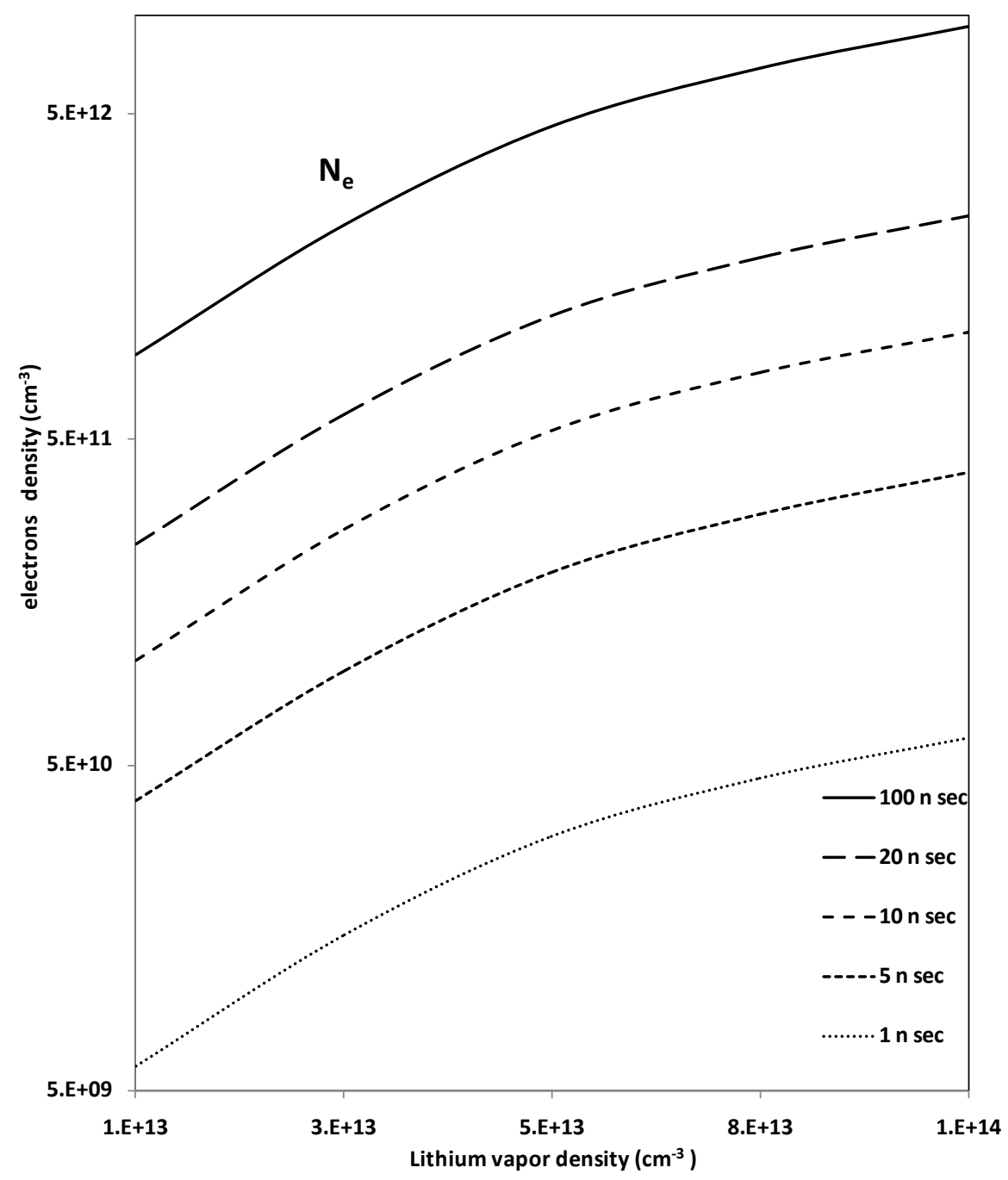

Figure 8. Variation of electrons density $\mathrm{N}_{\mathrm{e}}$ with Lithium vapor density $\mathrm{N}_{\mathrm{o}}$ at different time intervals and laser power $1 \times 10^{5} \mathrm{~W} \cdot \mathrm{cm}^{-2}$.

$$
\begin{gathered}
\operatorname{Li}(3 \mathrm{~d}) \rightarrow \operatorname{Li}(2 \mathrm{p})+\mathrm{h} v_{610.4 n m} \\
\mathrm{Li}(2 \mathrm{p})+\mathrm{Li}(2 \mathrm{p}) \rightarrow \mathrm{Li}(3 \mathrm{~d}, 3 \mathrm{p})+\mathrm{Li}(2 \mathrm{~s}) \\
\mathrm{Li}(3 \mathrm{~d}, 3 \mathrm{p})+\mathrm{h} v_{670.8} \rightarrow \mathrm{Li}^{+}+\mathrm{e}
\end{gathered}
$$

The third one is Penning ionization: $\mathrm{Li}(3 \mathrm{~d})+\mathrm{Li}(3 \mathrm{~d})+\mathrm{h} v_{639.1} \rightarrow \mathrm{Li}(2 \mathrm{~s})+\mathrm{Li}^{+}+\mathrm{e}$

In general, during the early stages electrons are created at a high rate through photoionization and collisional ionization processes. Beyond this time, the growth rate of the atomic ion becomes slower due to the competition between the generation of the electrons through Penning ionization or photoionization, as well collisional of the ground and excited losses of the ions by radiative recombination and three body recombination [20] [21]. In contrast, photoionization can play a remarkable role at a low ionization degree of the medium, when the basic mechanism of the $\operatorname{Li}(3 p, 3 d)$ population are energy pooling collisions: $\operatorname{Li}(2 p)+\operatorname{Li}(2 p) \rightarrow \operatorname{Li}(2 s)+\operatorname{Li}(3 p, 3 d)$ [39]. Through this process electron excitation prevails when $k_{E P} N(2 p)>k_{2 p-(3 p, 3 d)} n_{e}$ where $k_{E P}$ is the energy pooling rate coefficient. As far as we know, there is no definite value for this constant for lithium. The considered reaction is an endothermic one. For the pooling reaction with resonant $\mathrm{Cs}$ atoms a similar energy gap $\left(\Delta \mathrm{E}_{\mathrm{p}}\right.$ $\sim 0.18 \mathrm{eV}$ ) the reaction constants are of an order $\mathrm{k}_{\mathrm{EP}} \sim\left(10^{-11}-10^{-12}\right) \mathrm{cm}^{3} \cdot \mathrm{s}^{-1}$ [40]. When we employ this value to 


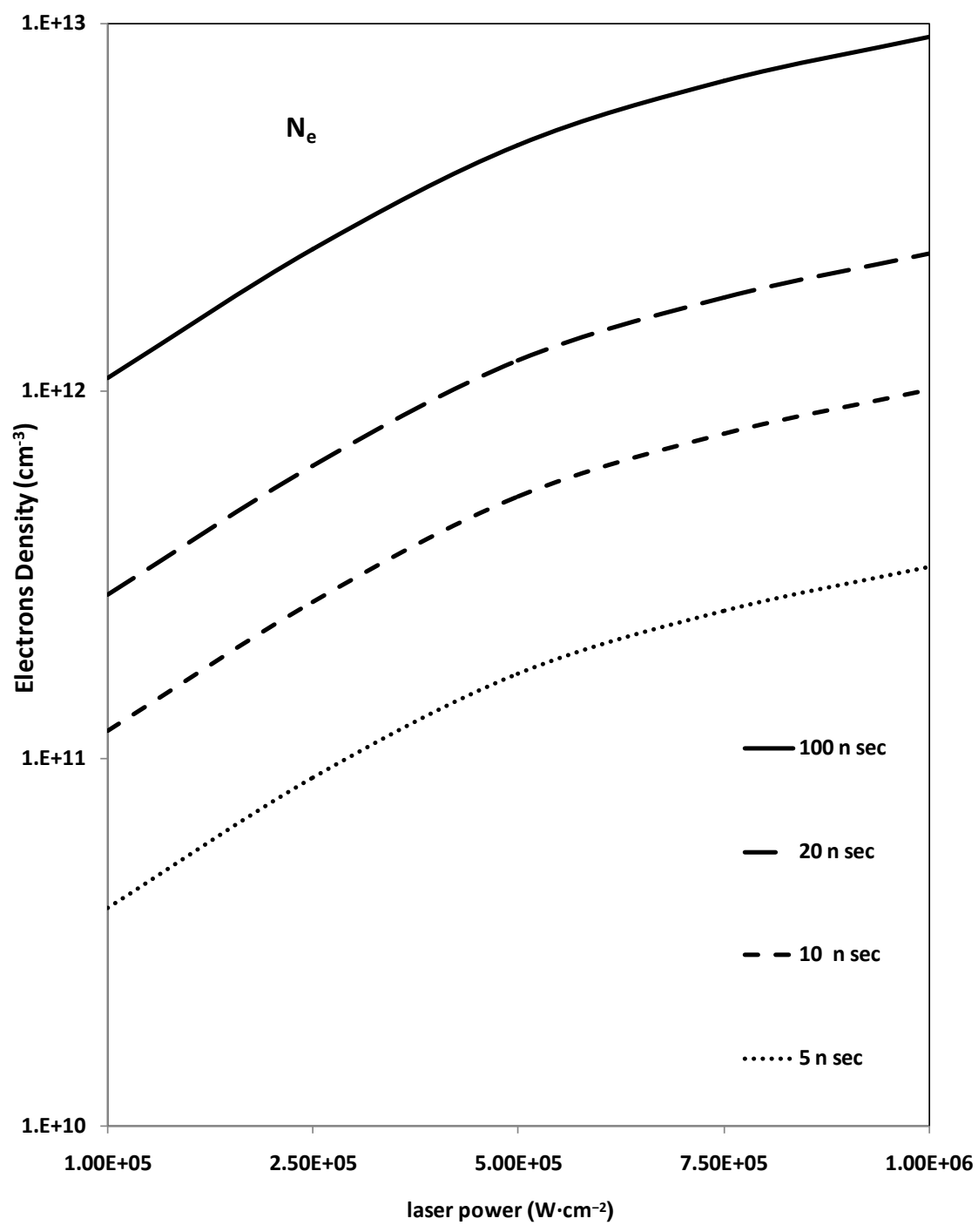

Figure 9. Variation of electrons density $\mathrm{N}_{\mathrm{e}}$ with laser power at different time intervals and lithium vapor density $3 \times 10^{13} \mathrm{~cm}^{-3}$.

make estimations for the reaction with lithium we find that under optical saturation potoionization processes can be the dominant processes in ionization processes.

Similarly, energy pooling collisions play a dual role as they deplete the lower states and simultaneously populate the upper states of interest, thus doubling the effect. In fact the two process, (superelastic transfer to the free electrons and energy pooling collisions) work in tandem to create qusicontinuous population inversions.

To give a deeper understanding of the role played by the physical processes in the electron growth rate and to confirm these results we compared our relation with that which obtained by McGeoch [24]. He applied his simple kinetic model of optically pumped lithium plasma to calculate the time evolution of the electron density which created during the interaction of lithium vapor with laser radiation. From Figure 11 it is seen that our results showed the same trend as those calculated by McGeoch [24], where their values display reasonable consistency over the whole range time. This in turn verified the validity of the model to investigate the Electron energy distribution function (EEDF) in lithium vapor excitation at $2 s \rightarrow 3 d$ two-photon resonance.

\section{Conclusion}

We have carried out a computational study of the influence of collisional ionization and collisional excitation processes which occur in lithium vapour under two-photon excitation of the $\operatorname{Li}(3 \mathrm{~d})$ state at $639.1 \mathrm{~nm}$. We have 


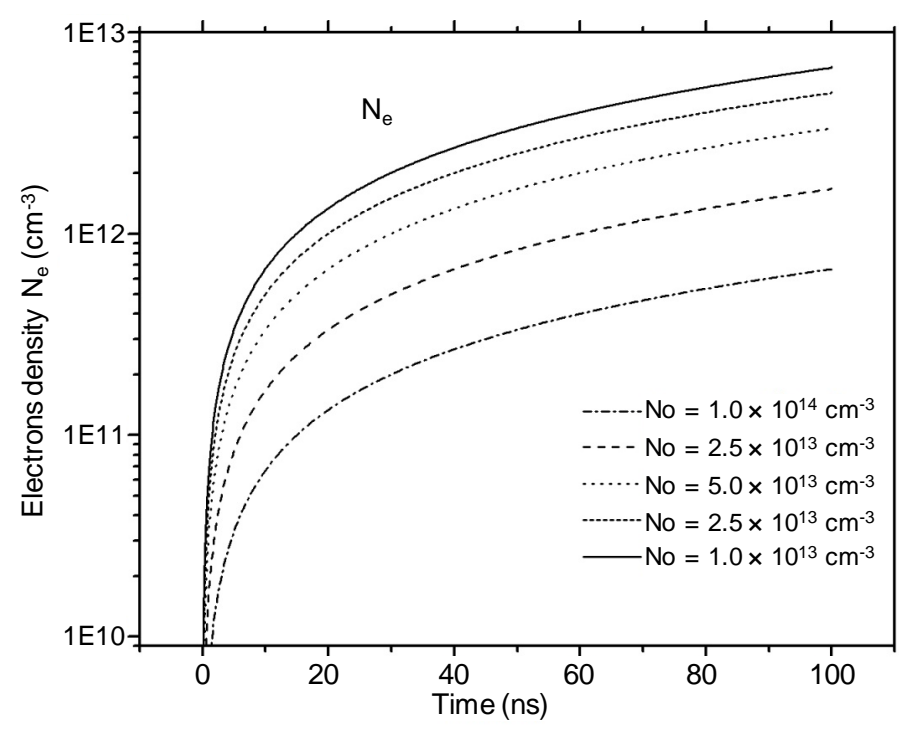

Figure 10. Time evolution of electrons density $\mathrm{N}_{\mathrm{e}}$ at different lithium vapor densities and laser power $1 \times 10^{5} \mathrm{~W} \cdot \mathrm{cm}^{-2}$.

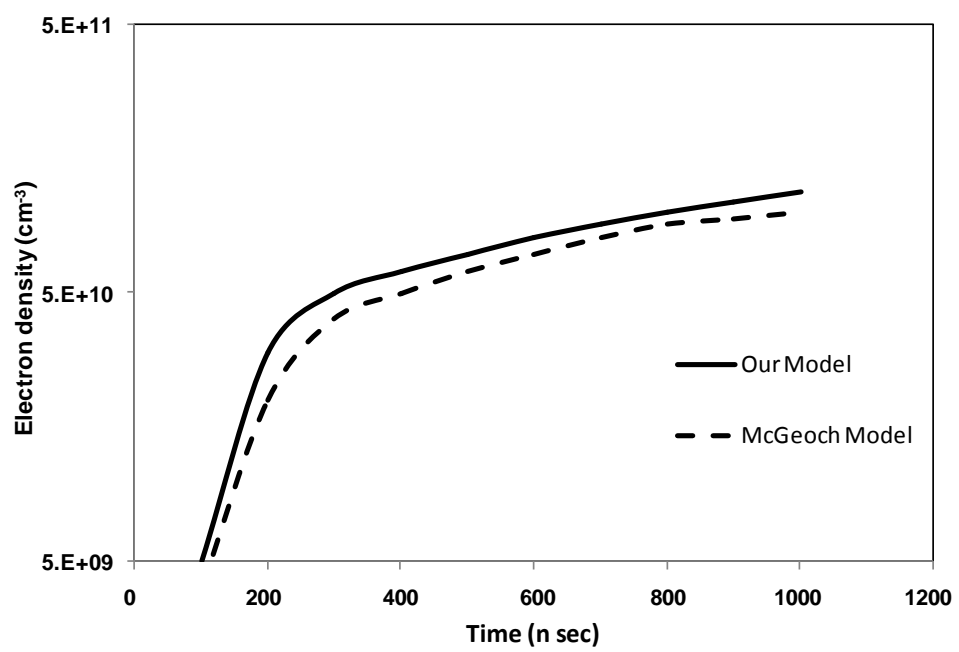

Figure 11. Comparison between the calculated Electron density of our model and that obtained by McGeoch [24] model at Laser pulse $=20$ ns and lithium vapor density $\mathrm{Li}=1 \times 10^{13} \mathrm{~cm}^{-3}$.

calculated the electron energy distribution function as well as the molecular ions and atomic ions for lithium atom densities in the range $\left(10^{13}-10^{14} \mathrm{~cm}^{-3}\right)$ and laser powers $\left(10^{5}-10^{6} \mathrm{~W} \cdot \mathrm{cm}^{-2}\right)$. The results confirm a satisfactory description of the experimentally observed behavior. At atomic density of $10^{14} \mathrm{~cm}^{-3}$ radiation population of the $\mathrm{Li}(2 \mathrm{p})$ state dominates over the collisional energy transfer (REP). The reverse energy pooling as a source for large pool of $\mathrm{Li}(2 \mathrm{p})$ atoms could be important at large atom densities. The nonlinear dependence of the electron energy distribution function on the lithium vapor density indicates that collisional processes, such as laser induced Penning ionization, associative ionization, Photoionization, as well as energy pooling collisions (which play role in populating the 3p and 3d states) form the plasma. The high energy of the EEDF had a non-equilibrium shape. This was caused by relaxation of fast electrons produced by super-elastic collisions with residual excited atoms. The model may be useful in a laser induced plasma or discharge experiments.

\section{References}

[1] Gorbunov, N.A., Grochola, A., Kruk, P., Pietruczuk, A. and Stacewicz, T. (2002) Studies of Electron Energy Distribu- 
tion in Plasma Produced by a Resonant Laser Pulse. Plasma Sources Science and Technology, 11, 492-497. http://dx.doi.org/10.1088/0963-0252/11/4/316

[2] Hassanien, A., Sizyuk, V. and Sizuk, T. (2011) The Effect of Critical Plasma Densities of Laser-Produced Plasma on Production of Extreme Ultraviolet Radiation. IEEE Transations on Plasma Science, 39, 2810-2811.

[3] Bartirmoro, R., Bombarada, F. and Giannella, R. (1985) Spectroscopic Study of Nonthermal Plasmas. Spectroscopic Study of Nonthermal Plasmas, 32, 531-537. http://dx.doi.org/10.1103/PhysRevA.32.531

[4] Liu, J.M., De Groot, J.S., Matte, J.P., Johnston, T.W., and Drake, R.P. (1994) Electron Heat Transport with NonMaxwellian Distributions. Physics of Plasmas, 1, 3570-3576. http://dx.doi.org/10.1063/1.870892

[5] Zhidkov, A.G., Sasaki, A., Tajima, T., Auguste, T., D’Olivera, P., Hulin, S., Monot, P., Faenov, A.Y., Pikuz, T.A. and Skoobelev, I.Y. (1999) Direct Spectroscopic Observation of Multiple-Charged-Ion Acceleration by an Intense Femtosecond-Pulse Laser, Physical Review E, 60,3273-3278. http://dx.doi.org/10.1103/PhysRevE.60.3273

[6] Zhidkov, A.G., Sasaki, A., Fukumoto, I., Tajima, T., Auguste, T., D’Olivera, P., Hulin, S., Monot, P., Faenov, A.Y., Pikuz, T.A. and Skobelev, I.Y. (2001) Pulse Duration Effect on the Distribution of Energetic Particles Produced by Intense Femtosecond Laser Pulses Irradiating Solids. Physics of Plasmas, 8, 3718-3723.

[7] Whitney, K.G. and Pulsifier, P.E. (1993) Plasma Conditions for Non-Maxwellian Electron Distributions in High Current Discharges and Laser-Produced Plasmas. Physical Review E, 47, 1968-1976. http://dx.doi.org/10.1103/PhysRevE.47.1968

[8] Choi, P., Deeney, C, and Wong, C.S. (1988) Absolute Timing of a Relativistic Electron Beam in a Plasma Focus. Physics Letters A, 128, 80-83. http://dx.doi.org/10.1016/0375-9601(88)91048-1

[9] Kantsyrev, V.L., Fedin, D.A., Shlyaptseva, A.S., Hansen, S., Chamberlain, D. and Ouart, N. (2003) Energetic Electron Beam Generation and Anisotropy of Spectra and Spatial Distribution of Hard X-Ray Emission from 0.9 - 1.0 MA High-Z X-Pinches. Physics of Plasmas, 10, 2519-2526. http://dx.doi.org/10.1063/1.1572489

[10] Pereira, N.R. and Whitney, K.G. (1988) Non-Maxwellian Electron-Energy Distribution Due to Inelastic Collisions in a Z-Pinch Plasma. Physical Review A, 38, 319-327. http://dx.doi.org/10.1103/PhysRevA.38.319

[11] McTienan, J.M. and Petrosian, V. (1990) The Behavior of Beams of Relativistic Nonthermal Electrons under the Influence of Collisions and Synchrotron Losses. Astrophysical Journal, 359, 541-546.

[12] Kato, T., Fujiwara, T. and Hanaoka, Y. (1998) X-Ray Spectral Analysis of Yohkoh Bragg Crystal Spectrograph Data on a 1992 September 6 Flare: The Blueshift Component and Ion Abundances. Astrophysical Journal, 492, 822-832. http://dx.doi.org/10.1086/305047

[13] Baring, M.G. (1991) The Collisional Acceleration of Relativistic Electrons in the Central Regions of Active Galactic Nuclei. Monthly Notices of the Royal Astronomical Society, 253, 388-400. http://dx.doi.org/10.1093/mnras/253.3.388

[14] Gorbunov, A.N. and Stacewicz, T. (2000) Photo EMF Observed upon the Laser Resonance Excitation of Sodium Vapors. Technical Physics Letters, 26, 654-655. http://dx.doi.org/10.1134/1.1307803

[15] Gorbunov, A.N. and Stacewicz, T. (2001) Observation of an Electromotive Force in a Decaying Photoresonance Plasma of Sodium Vapors. High Temperature, 39, 623-625. http://dx.doi.org/10.1023/A:1017956827981

[16] Gorbunov, A.N., Melnikov, S., Smurov, I. and Bray, I. (2001) Ionization Kinetics of Optically Excited Lithium Vapor under Conditions of Negative Electron Mobility. Journal of Physics D: Applied Physics, 34, 1379-1388. http://dx.doi.org/10.1088/0022-3727/34/9/315

[17] Stwalley, W.C. and Bahns, J.T. (1993) Atomic, Molecular, and Photonic Processes in Laser-Induced Plasmas in Alkali Metal Vapors. Laser and Particle Beams, 11, 185-204.

[18] Veza, D. and Sansonetti, C.J. (1992) Ionization of Lithium Vapor by CW Quasiresonant Laser Light. Zeitschrift für Physik D Atoms, Molecules and Clusters, 22, 463-470. http://dx.doi.org/10.1007/BF01426088

[19] Koch, M.E. and Collins, C.B. (1979) Space-Charge Ion Detection of Multiphoton Absorption Phenomena in Lithium Vapor. Physical Review A, 19, 1098-1105. http://dx.doi.org/10.1103/PhysRevA.19.1098

[20] Skenderovic, H., Labazan, I., Milosevic, S. and Pichler, G. (2000) Laser-Ignited Glow Discharge in Lithium Vapor. Physical Review A, 62, 0527071-7.

[21] Labazan, I. and Milosevic, S. (2000) Lithium Vapour Excitation at 2S $\rightarrow$ 3D Two-Photon Resonance. European Physical Journal D, 8, 41-47.

[22] Measures, R.M. and Cardinal, P.G. (1981) Laser Ionization Based on Resonance Saturation. A Simple Model Description. Physical Review A, 23, 804-815. http://dx.doi.org/10.1103/PhysRevA.23.804

[23] Stacewicz, T. and Topulos, G. (1988) Ionization of Sodium Vapour by Nanosecond Resonant Laser Pulses. Physica Scripta, 38, 560-563. http://dx.doi.org/10.1088/0031-8949/38/4/010

[24] McGeoch, M.W. (1989) Processes in a Lithium Negative Ion Source. SPIE Symposium on Innovative Science and 
Technology, Los Angeles, January 1989, 1-26.

[25] Mahmoud, M.A. (2008) Kinetics of $\mathrm{Rb}^{+}$and $\mathrm{Rb}^{+}$Formation in Laser-Excited Rubidium Vapor. Central European Journal of Physics, 6, 530-538. http://dx.doi.org/10.2478/s11534-008-0074-5

[26] Mahmoud, M.A., El Tabal, A. and Nady, M. (2012) Collisional Ionization in Lithium Vapor Excited by Nanosecond Laser Pulses. Acta Physica Polinica A, 122, 71-77.

[27] Bezuglov, N.N., Klyucharev, A.N. and Sheverev, V.A. (1987) Associative Ionization Rate Constants Measured in Cell and Beam Experiments. Journal of Physics B: Atomic and Molecular Physics, 20, 2497-2513. http://dx.doi.org/10.1088/0022-3700/20/11/018

[28] Mahmoud, M.A. (2005) Electron Energy Distribution Function in Laser-Excited Rubidium Atoms. Journal of Physics B: Atomic, Molecular and Optical Physics, 38, 1545-1556. http://dx.doi.org/10.1088/0953-4075/38/10/012

[29] Oxenius, J. (1986) Kinetic Theory of Particles and Photons. Springer, Berlin. http://dx.doi.org/10.1007/978-3-642-70728-5

[30] Vriens, L. and Smeets, A.H.M. (1980) Cross-Section and Rate Formulas for Electron-Impact Ionization, Excitation, Deexcitation, and Total Depopulation of Excited Atoms. Physical Review A, 22, 940-951. http://dx.doi.org/10.1103/PhysRevA.22.940

[31] Drawin, W.H. (1967) Collision and Transport Cross-Sections. Association Euratom CEA, 92 Fontenay-aux Roses, France, 496-506.

[32] Tisone, G.C. and Hargis Jr., P.J. (1987) Laser Absorption and Fluorescence Studies of the Lithium 2S - 3D Transition. AIP Conference Proceedings, Vol. 160, AIP Press, New York, 404-417.

[33] Wiese, W.L., Smith, M.W. and Glennon, B.M. (1966) Atomic Transition Probabilities. Vol. I, National Bureau of Standards, Washington, DC, 17.

[34] Wiese, W.L. and Fuhr, J.R. (2009) Accurate Atomic Transition Probabilities for Hydrogen, Helium, and Lithium. Journal of Physical and Chemical Reference Data, 38, 565. http://dx.doi.org/10.1063/1.3077727

[35] McGeoch, M.W., Schiler, R.E. and Chawla, G.K. (1988) Associative Ionization with Cold Rydberg Lithium Atoms. Physical Review Letters, 61, 2088-2091. http://dx.doi.org/10.1103/PhysRevLett.61.2088

[36] Jabbour, Z.J., Namiotka, R.K., Huennekens, J., Allegrini, M., Milosevic, S. and De Tomasi, F. (1996) Energy Pooling Collisions in Cesium: 6P $+6 \mathrm{PJ} \rightarrow 6 \mathrm{~S}+(\mathrm{nl}=7 \mathrm{P}, 6 \mathrm{D}, 8 \mathrm{~S}, 4 \mathrm{~F})$. Physical Review A, 54, 1372-1384.

[37] De Filippo, G., Guldberg-Kjaer, S., Milosevic, S., Pedersen, J.O.P. and Allegrini, M. (1998) Reverse Energy-Pooling in K-Na Mixture. Physical Review A, 57, 255-266.

[38] Aymar, M., Luc-Koenig, E. and Combet Farnoux, F. (1976) Theoretical Investigation on Photoionization from Rydberg States of Lithium, Sodium and Potassium. Journal of Physics B: Atomic and Molecular Physics, 9, 1279-1291. http://dx.doi.org/10.1088/0022-3700/9/8/013

[39] He, C. and Bernheim, R.A. (1992) Energy Transfer and Energy Pooling from $2{ }^{2} \mathrm{P}$ 3/2,1/2, Excited Li Atoms in Li Vapor. Chemical Physics Letters, 190, 494-506.

[40] Klucharev, A.N. and Vujnovic, A. (1990) Chemi-Ionization in Thermal-Energy Binary Collisions of Optically Excited Atoms. Physics Reports, 185, 57-81. http://dx.doi.org/10.1016/0370-1573(90)90112-F 
Scientific Research Publishing (SCIRP) is one of the largest Open Access journal publishers. It is currently publishing more than 200 open access, online, peer-reviewed journals covering a wide range of academic disciplines. SCIRP serves the worldwide academic communities and contributes to the progress and application of science with its publication.

Other selected journals from SCIRP are listed as below. Submit your manuscript to us via either submit@scirp.org or Online Submission Portal.
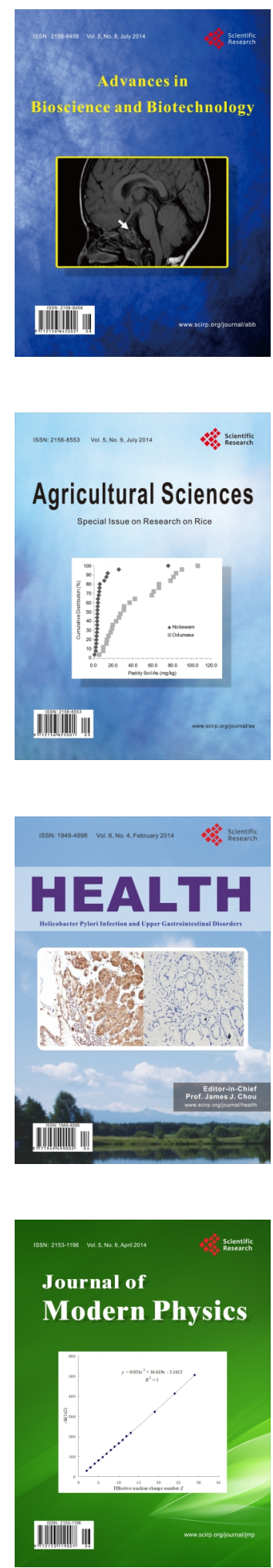
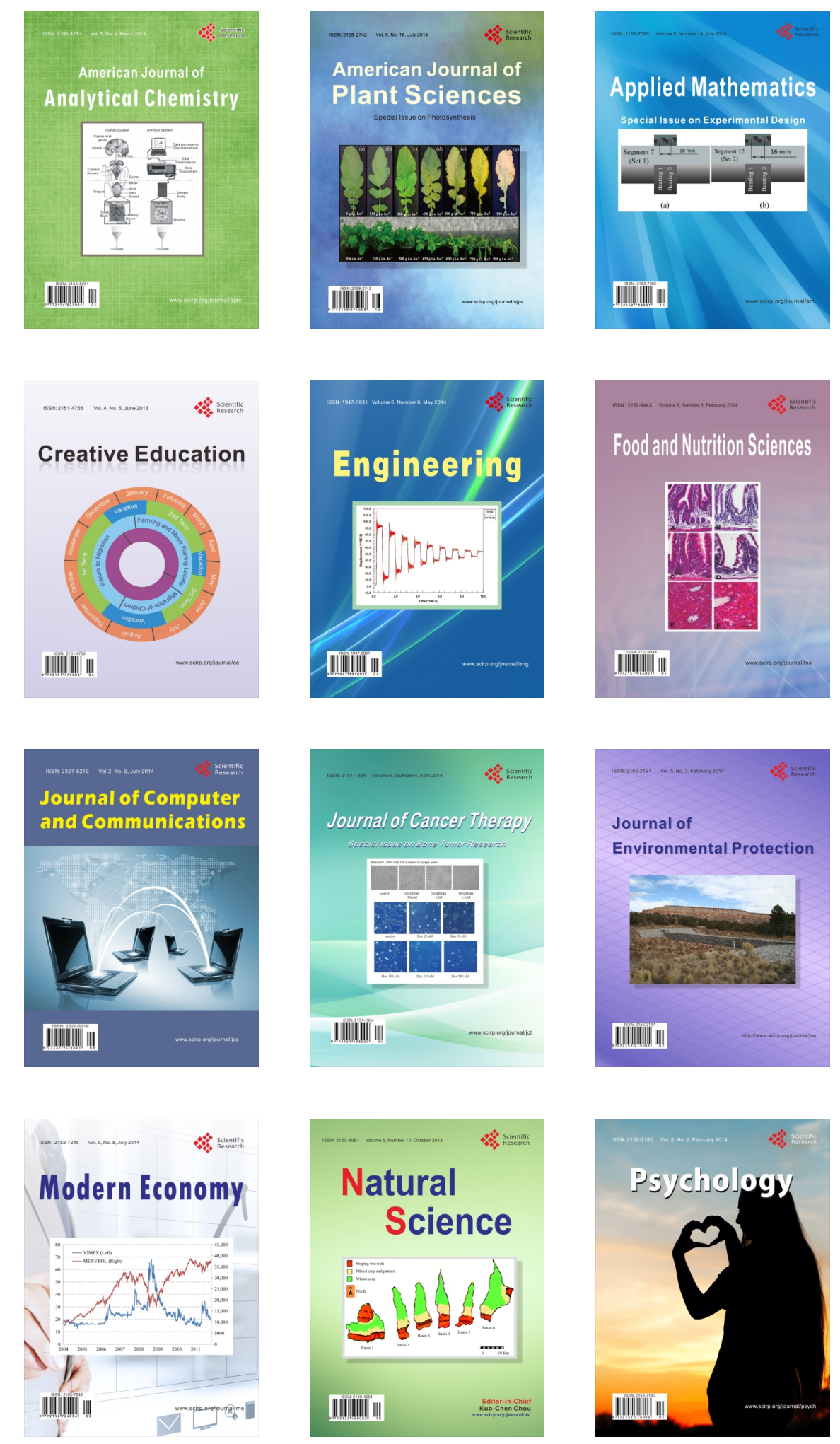